\title{
A 16-year global climate data record of total column water vapour generated from OMI observations in the visible blue spectral range
}

\author{
Christian Borger, Steffen Beirle, and Thomas Wagner \\ Satellite Remote Sensing Group, Max Planck Institute for Chemistry, Mainz, Germany \\ Correspondence: Christian Borger (christian.borger@mpic.de) and Thomas Wagner (thomas.wagner@mpic.de)
}

\begin{abstract}
We present a long-term data set of $1^{\circ} \times 1^{\circ}$ monthly mean total column water vapour (TCWV) based on global measurements of the Ozone Monitoring Instrument (OMI) covering the time range from January 2005 to December 2020.

In comparison to the retrieval algorithm of Borger et al. (2020) several modifications and filters have been applied accounting for instrumental issues (such as OMI's "row-anomaly") or the inferior quality of solar reference spectra. For instance, to overcome the problems of low quality reference spectra, the daily solar irradiance spectrum is replaced by an annually varying mean Earthshine radiance obtained in December over Antarctica. For the TCWV data set only measurements are taken into account for which the effective cloud fraction $<20 \%$, the AMF $>0.1$, the ground pixel is snow- and ice-free, and the OMI row is not affected by the "row-anomaly" over the complete time range of the data set. The individual TCWV measurements are then gridded to a regular $1^{\circ} \times 1^{\circ}$ lattice, from which the monthly means are calculated.

In a comprehensive validation study we demonstrate that the OMI TCWV data set is in good agreement to reference data sets of ERA5, RSS SSM/I, and ESA CCI Water Vapour CDR-2: over ocean ordinary least squares (OLS) as well as orthogonal distance regressions (ODR) indicate slopes close to unity with very small offsets and high correlation coefficients of around 0.98. However, over land, distinctive positive deviations are obtained especially within the tropics with relative deviations of approximately $+10 \%$ likely caused by uncertainties in the retrieval input data (surface albedo, cloud information) due to frequent cloud contamination in these regions. Nevertheless, a temporal stability analysis proves that the OMI TCWV data set is consistent with the temporal changes of the reference data sets and shows no significant deviation trends.

Since the TCWV retrieval can be easily applied to further satellite missions, additional TCWV data sets can be created from past missions such as GOME-1 or SCIAMACHY, which under consideration of systematic differences (e.g. due to different observation times) can be combined with the OMI TCWV data set in order to create a data record that would cover a time span from 1995 to the present. Moreover, the TCWV retrieval will also work for all missions dedicated to $\mathrm{NO}_{2}$ in future such as Sentinel-5 on MetOp-SG.
\end{abstract}

The MPIC OMI total column water vapour (TCWV) climate data record is available at https://doi.org/10.5281/zenodo.5776718 (Borger et al., 2021b). 
https://doi.org/10.5194/essd-2021-319

Preprint. Discussion started: 16 December 2021

(c) Author(s) 2021. CC BY 4.0 License.

(c) (i)

\section{Introduction}

Water vapour is the most important natural greenhouse gas in the Earth's atmosphere altering the Earth's energy balance by playing a dominant role in the atmospheric thermal opacity and having a major amplifying influence on several factors of anthropogenic climate change through various feedback mechanisms (Kiehl and Trenberth, 1997; Randall et al., 2007; Trenberth et al., 2009). Though its great importance not only on processes on global/climate scale, the complex interactions between the components of the hydrological cycle (including water vapour) and the atmosphere are still one of major challenges of climate modelling and for a better understanding of the Earth's climate system in general (Stevens and Bony, 2013). Moreover, the amount and distribution of water vapour are highly variable, so that for global observations these must also be measured with high spatiotemporal resolution. Considering that changes in water vapour are closely linked to changes in temperature via the Clausius-Clapeyron equation, i.e. for typical atmospheric conditions a temperature increase of $1 \mathrm{~K}$ yields an increase in the water vapour concentration by approximately 6-7\% (Held and Soden, 2000), it is essential to monitor the variability and change of the amount and distribution of water vapour on global scale accurately.

To observe the water vapour distribution on global scale, satellite measurements provide invaluable information. Due to its spectroscopic absorption properties, water vapour can be retrieved from satellite spectra in various different spectral ranges, ranging from the radio (e.g. Kursinski et al., 1997), microwave (e.g. Rosenkranz, 2001), thermal infrared (e.g. Susskind et al., 2003)), short and near-infrared (e.g. Bennartz and Fischer, 2001; Gao and Kaufman, 2003) to the visible spectral range (e.g.

Within the past decade, substantial progress has been made to retrieve total column water vapour (TCWV) within the visible blue spectral range (e.g. Wagner et al., 2013; Wang et al., 2019; Borger et al., 2020; Chan et al., 2020) allowing to make use of measurements from satellite instruments like TROPOMI (Veefkind et al., 2012) and even GOME-2 (Munro et al., 2016) for which so far only retrievals in the visible red and near-infrared spectral range have been available. In comparison to these aforementioned spectral ranges, TCWV retrievals in the visible "blue" have several advatanges, for instance similar sensitivity for the near-surface layers over land and ocean due to a more homogenous surface albedo distribution than at longer wavelengths (Koelemeijer et al., 2003; Wagner et al., 2013; Tilstra et al., 2017). Moreover, any satellite mission dedicated to $\mathrm{NO}_{2}$ monitoring is covering this spectral range.

For investigations of climate change or global warming, respectively, the Ozone Monitoring Instrument (Levelt et al., 2006, 2018) onboard NASA's Aura satellite is particularly interesting: launched in July 2004 it offers an almost continuous measurement data record of more than 16 years up until today. In this study, we make use of OMI's long-term data record and retrieve total column water vapour (TCWV) from its measurements in the visible blue spectral range in order to generate a climate data set. The paper is structured as follows: in Sect. 2 we describe the data set generation and briefly explain the retrieval methodology and the applied modifications in comparison to the TCWV retrieval from Borger et al. (2020). Then, in Sect. 3 we characterize the data set via a validation study to the various different reference TCWV data sets and also analyze its temporal stability. Finally, we briefly summarize our results in Sect. 4 and draw conclusions. 


\section{OMI TCWV data set}

\subsection{Ozone Monitoring Instrument}

The Ozone Monitoring Instrument OMI (Levelt et al., 2006, 2018) onboard NASA's Aura satellite is a nadir-looking UV-vis pushbroom spectrometer that measures the Earth's radiance spectrum from $270-500 \mathrm{~nm}$ with a spectral resolution of approximately $0.5 \mathrm{~nm}$ following a sun-synchronous orbit with an equator crossing time around 13:30 LT. The instrument employs a 2D CCD consisting of 60 across-track rows which in total cover a swath width of approximately $2600 \mathrm{~km}$ with a spatial resolution of $24 \mathrm{~km} \times 13 \mathrm{~km}$ at nadir increasing to $24 \mathrm{~km} \times 160 \mathrm{~km}$ towards the edges of the swath. Launched in July 2004, OMI provides an almost continuous measurement record until today with more than 90000 orbits.

However, since July 2007 OMI has suffered from the so-called "row-anomaly", a dynamic artefact causing abnormally low radiance readings in the across-track rows, i.e. several rows of the CCD detector receive less light from the Earth, and some other rows appear to receive sunlight scattered off a peeling piece of spacecraft insulation. One plausible explanation for these effects is a partial obscuration of the entrance port by insulating layer material that may have come loose on the outside of the instrument (Schenkeveld et al., 2017; Boersma et al., 2018). Thus, in this study, the affected measurements are excluded for the entire period of the evaluation.

\subsection{Methodology and modifications of the spectral analysis}

To retrieve total column water vapour (TCWV) from UV-vis spectra from OMI, we apply the TCWV retrieval of Borger et al. (2020) developed for the TROPOspheric Monitoring Instrument (TROPOMI) onboard Sentinel-5P. The retrieval is based on the principles of Different Optical Absorption Spectroscopy (DOAS, Platt and Stutz, 2008) with a fit window between 430-450 nm and consists of the common two-step DOAS approach: first, the absorption along the light path is calculated:

$\ln \left(\frac{I}{I_{0}}\right) \approx-\sum_{i} \sigma_{i}(\lambda) \cdot \operatorname{SCD}_{i}+\Psi+\Phi$

where $I$ and $I_{0}$ represent the solar irradiance and the radiance backscattered from Earth, respectively, and $i$ denotes the index of a trace gas of interest, $\sigma_{i}(\lambda)$ its respective molecular absorption cross section, $\mathrm{SCD}_{\mathrm{i}}=\int_{s} c_{i} d s$ its concentration integrated along the light path $s$ (the so called slant column density), $\Psi$ summarizing terms accounting for the Ring effect and additional pseudo-absorbers, and $\Phi$ a closure polynomial accounting for Mie and Rayleigh scattering as well as parts of the low-frequency contributions of the trace gas cross sections.

Second, to convert the slant column density to a vertical column density (VCD), we apply the so called airmass factor (AMF):

$\mathrm{VCD}=\frac{\mathrm{SCD}}{\mathrm{AMF}}$

The AMF accounts for the non-trivial effects of atmospheric radiative transfer and depends on the conditions of the retrieval scenario (i.e. aerosol and cloud effects, viewing geometry, and surface properties) as well as the profile shape of the trace gas of interest. The algorithm of Borger et al. (2020) makes use of the relation between the $\mathrm{H}_{2} \mathrm{O}$ VCD and the profile shape and iteratively finds the optimal VCD by assuming an exponential water vapour profile shape. 
https://doi.org/10.5194/essd-2021-319

Preprint. Discussion started: 16 December 2021

(c) Author(s) 2021. CC BY 4.0 License.

(c) (i)

For the application of the algorithm to OMI measurements several modifications had to be applied to the algorithm of Borger et al. (2020). For climate studies such as trend analyses it is evident to provide a consistent data record. Thus, all rows that have ever been affected by the so called "row-anomaly" are excluded from the data set for the complete time series, which corresponds to approximately half of the OMI swath. Also, instead of a daily solar irradiance an Earthshine radiance is used as reference spectrum within the DOAS analysis. The rationale for using an Earthshine radiance over a solar irradiance is as follows:

- The daily OMI solar irradiance spectra (OML1BIRR version 3) are very noisy and have several gaps causing high $\mathrm{H}_{2} \mathrm{O}$ SCD fit errors and thus leading to an overall poor quality of the $\mathrm{H}_{2} \mathrm{O}$ VCD data set.

- By using an annual mean solar irradiance spectrum from the year 2005 (also used during the QA4ECV project; Boersma et al., 2018) a good fit quality can be obtained, however, OMI is also suffering from degradation effects (Schenkeveld et al., 2017). Thus, for the case of climate trend analyses it will be almost impossible to disentangle if a trend signal originates from the spectral degradation of OMI or indeed from a geophysical trend (see also Fig. A1). By using an Earthshine radiance as reference spectrum these degradation effects will largely cancel out.

- By using an Earthshine radiance as reference spectrum, also the across-track biases within the OMI swath are strongly reduced (see Panel (c) in Fig. 1) and consequently no destriping is necessary during post-processing (see also Anand et al., 2015).

- However, as a disadvantage of the use of Earthshine spectra, the retrieved $\mathrm{H}_{2} \mathrm{O}$ slant columns do not represent absolute slant columns because the Earthshine reference spectra also contain $\mathrm{H}_{2} \mathrm{O}$ absorptions. Hence, a slant column representative for the chosen reference sector has to be added to the retrieved values.

For the creation of annual Earthshine reference spectra we selected the Antarctic continent as reference sector (high surface albedo due to snow and ice cover) and the time period of December (i.e. during austral summer) yielding a relatively high signal-to-noise ratio for our radiance measurements despite large solar zenith angles. Furthermore, only pixels above an altitude of $2000 \mathrm{~m}$ above sea level are selected: as the air temperatures are very low there, the water vapour concentrations are very low as well, thus representing a reference atmosphere that is as dry as possible (i.e. the reference SCD or better saying the absolute value of its uncertainty has to be as minimal as possible). Also, to avoid the inclusion of noisy measurements (in particular from the descending part of the OMI orbit), only pixels with a solar zenith angle (SZA) $<80^{\circ}$ are considered. From these measurements we calculate the monthly-mean radiance for December for each year for every OMI row and then use the resulting reference spectra for the retrievals of the upcoming year.

Figure 1 illustrates the effect of different reference spectra on the $\mathrm{H}_{2} \mathrm{O}$ SCD distribution for an examplary orbit. Distinctive stripe patterns are prominent in particular when using the daily solar irradiance as reference spectrum (Panel (a) in Fig. 1). Although the usage of the annual-mean solar irradiance (Panel b) can reduce the strength of the stripes, they are still clearly visible. In contrast, no across-track stripes are detectable for the case of the Earthshine reference and overall the SCDs are also lower due to the $\mathrm{H}_{2} \mathrm{O}$ absorption in the Earthshine reference (Panel c). 
a) Daily solar irradiance

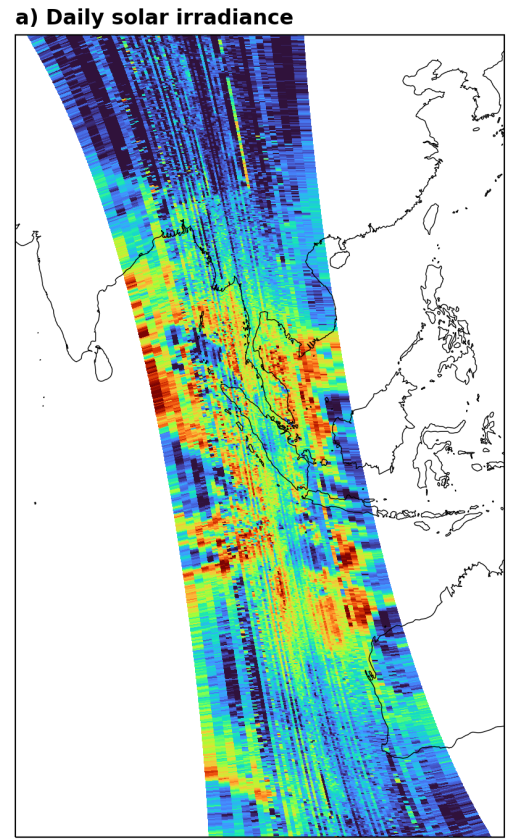

b) Annual-mean solar irradiance

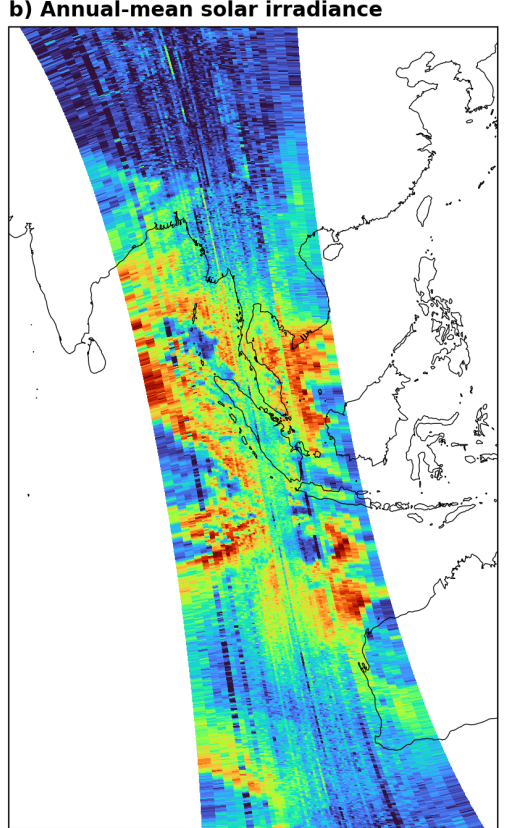

c) Earthshine reference

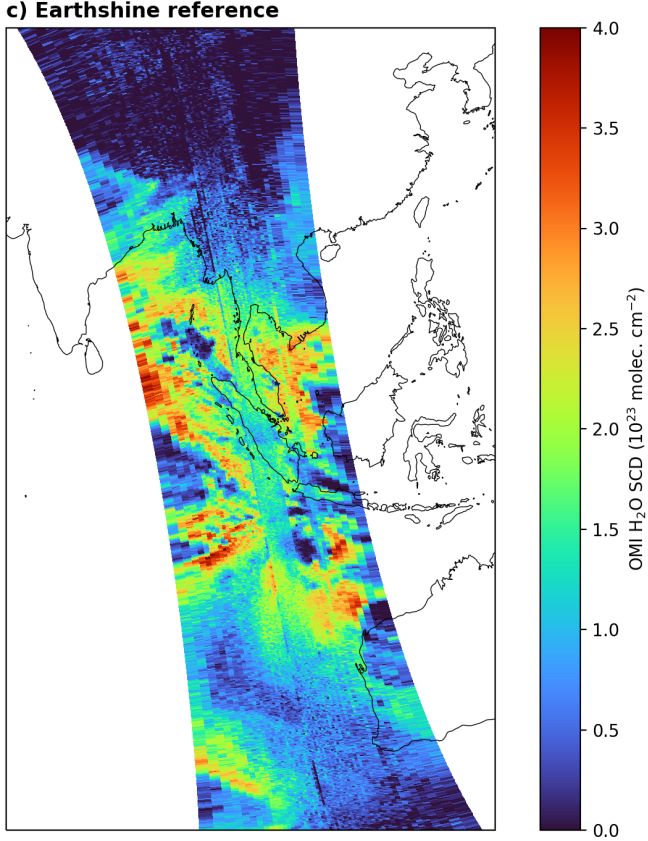

Figure 1. Examplary orbit showing the impact of different reference spectrum on the $\mathrm{OMI}_{2} \mathrm{O}$ SCD distribution: a) daily solar irradiance, b) annual-mean solar irradiance, and c) monthly mean Earthshine reference. Orbit 34382, date 01-01-2011.

Further details about destriping in general and a comparison of the temporal behaviour of the irradiance based and Earthshine SCD are available in Appendix A.

\subsection{VCD conversion and data set generation}

To account for the potential water vapour contamination within the Earthshine reference spectra, the SCDs based on the

Earthshine reference have to be corrected for the corresponding offset. In this study, we determine this offset for each row based on the difference of the Earthshine based SCDs and solar irradiance based SCDs for the first 5 years of OMI operation (see Appendix A). Equation (2) can then be rewritten as:

$\mathrm{VCD}=\frac{\mathrm{eSCD}+\Delta \mathrm{SCD}}{\mathrm{AMF}}$

where $\mathrm{SSCD}$ denotes the SCD derived using the Earthshine reference.

The AMFs are calculated as described in Borger et al. (2020). For the determination of the AMF, additional information about the retrieval scenario like cloud cover and surface properties is necessary. We use the cloud information from the OMI L2 $\mathrm{NO}_{2}$ product (OMNO2, Lamsal et al., 2021) and the modified OMI surface albedo version of Kleipool et al. (2008) as described in Borger et al. (2020). We also tested the surface albedo information from the OMNO2 product, however, within the framework of a trend analysis study (Borger et al., 2021a) we observed spatial artefacts in the surface albedo trends which likely arise 


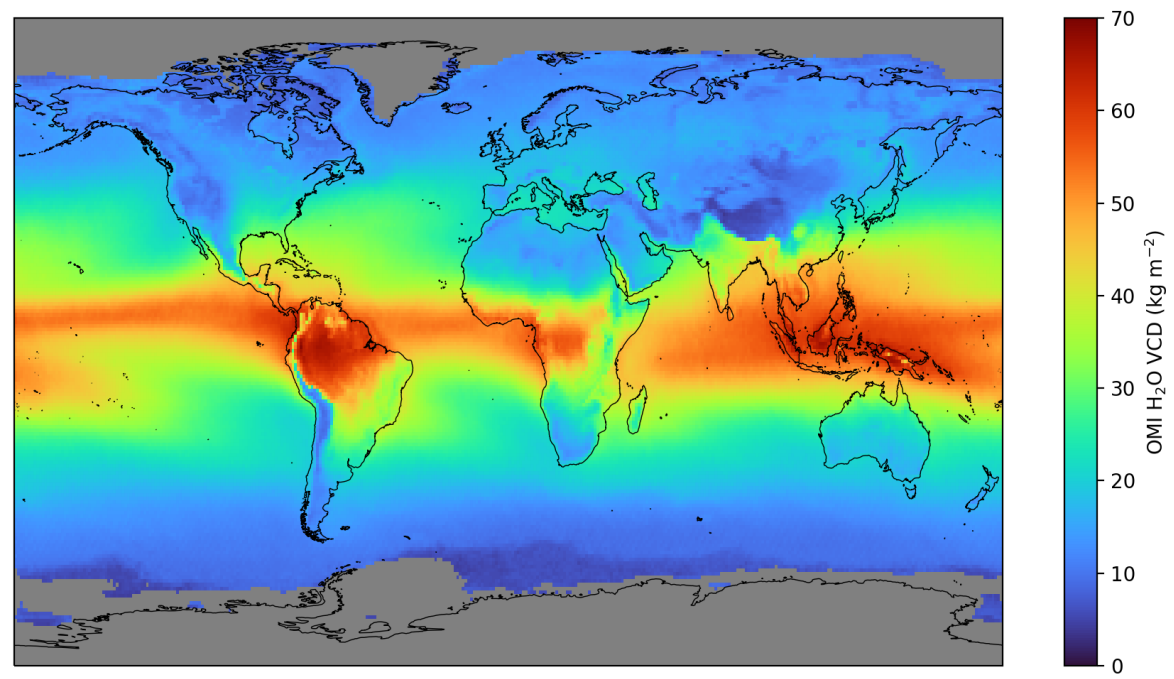

Figure 2. Global mean OMI $\mathrm{H}_{2} \mathrm{O}$ VCD distribution from 2005 until 2020 based on the OMI analysis using Earthshine reference spectra and corrected for the $\mathrm{H}_{2} \mathrm{O}$ SCD bias. Areas with no valid values are coloured grey.

from the use of an older version of the MODIS data for the albedo calculation (Lok Lamsal, personal communication). The distribution of TCWV trends is mainly determined by the trends in the SCD. The albedo or AMF trends usually only determine whether the trend signal becomes stronger or weaker, but this only affects trends over land, since an albedo climatology from Kleipool et al. (2008) is used over ocean. As the ice flags from the OMI processor sometimes indicate snow/ice-free surfaces over Antarctica or Greenland, we additionally use the monthly mean sea ice cover information from ERA5 (Hersbach et al., 2020) and the annual mean land cover information from MODIS Aqua (Sulla-Menashe et al., 2019).

To create the OMI TCWV data set, we have chosen the time range from January 2005 to December 2020 and only include observations with an effective cloud fraction $<20 \%$ and AMF $>0.1$. Furthermore, the pixels have to be free of snow and ice and must not be affected by the row anomaly. The results of every orbit are then gridded to a $1^{\circ} \times 1^{\circ}$ lattice for every day. From these daily grids, the monthly mean $\mathrm{H}_{2} \mathrm{O}$ VCD distributions are then calculated ensuring that a continuous TCWV time series is available for as many grid cells as possible.

Figure 2 shows the global mean $\mathrm{OMI}_{2} \mathrm{O}$ VCD averaged over the complete time range of the TCWV data set. The resulting distribution demonstrates that the retrieval is capable to capture the macroscale water vapour patterns like high VCD values in the tropics (in particular over the maritime continent) and low values towards the polar regions, but also characteristic regional patterns like the South Pacific convergence zone. 


\section{Validation}

To evaluate the overall quality of the OMI TCWV data set, we conducted a validation study for which we use the merged, 1-degree total precipitable water (TPW) data set version 7 from Remote Sensing Systems (RSS) (Mears et al., 2015; Wentz, 2015), TCWV data from the reanalysis model ERA5 (Hersbach et al., 2019, 2020), and the ESA Water Vapour CCI climate data record CDR-2 as reference. For the correlation analysis we perform an ordinary least-squares (OLS) linear regression and an orthogonal distance regression (ODR). In the case of the ODR it is necessary to use reasonable ratios of the relative errors of the compared data sets instead of using absolute errors in order to obtain meaningful results. Thus, for the sake of simplicity, we assume that the relative errors of the reference data sets over ocean are 5\%, over land 10\%, and for the OMI TCWV data set $20 \%$. We also tested other variants of error assumptions and it turned out that the exact choice of errors is negligible for the regression results.

\subsection{Intercomparison to RSS SSM/I}

The RSS data set consists of merged geophysical ocean products whereby the values are retrieved from various passive satellite microwave radiometers. These microwave radiometers have been intercalibrated at the brightness temperature level and the ocean products have been produced using a consistent processing methodology for all sensors (more details in Wentz, 2015; Mears et al., 2015).

The left panel in Fig. 3 depicts the 2D histogram from the comparison between the monthly mean values from RSS and the OMI TCWV data set. The data is distributed closely along the 1-to-1 diagonal (black dashed line) and yields a correlation coefficient of $\mathrm{R}=0.98$. The results of the linear (OLS, red solid line) and orthogonal distance regression (ODR, red dashed line) both indicate an overall very good agreement with slopes of 1.03 and 1.05, respectively. The right panel of Fig. 3 illustrates the zonally averaged monthly mean difference of OMI minus RSS TCWV within the latitude-time space. In general, the deviations between OMI and RSS are quite low with values between $\pm 2.5 \mathrm{~kg} \mathrm{~m}^{-2}$. Nevertheless, within the tropics (i.e. between -20 to $20^{\circ} \mathrm{N}$ ), distinctive periodic patterns of positive deviations are observable.

Figure 4 shows the global mean TCWV difference between OMI and RSS SSM/I over the complete time period of the OMI TCWV data set. Consistent with the findings from Fig. 3 highest positive deviations can be found in the tropical Pacific ocean and near the coastlines of South America whereas strongest negative deviations are obtained around the South Pacific convergence zone and East Siberian Sea. In the case of the tropical Pacific ocean the distribution of the systematic positive deviations matches quite well regions of cold water or of the so called "cold tongue". In the case of Central America or Atlantic ocean, a too low albedo could explain the systematic positive deviations.

Additional comparisons taking into account only valid grid cells according to the "common-mask" from ESA WV CCI CDR are presented in Appendix B. This mask filters regions where no continuous time series of data is available or where the data are affected by high uncertainties e.g. due to frequent cloud cover. If these regions are removed and therefore only high quality measurements are compared to each other, we obtain a much better agreement to the reference data set and the slight overestimation of $3-5 \%$ is reduced to $1-3 \%$. 

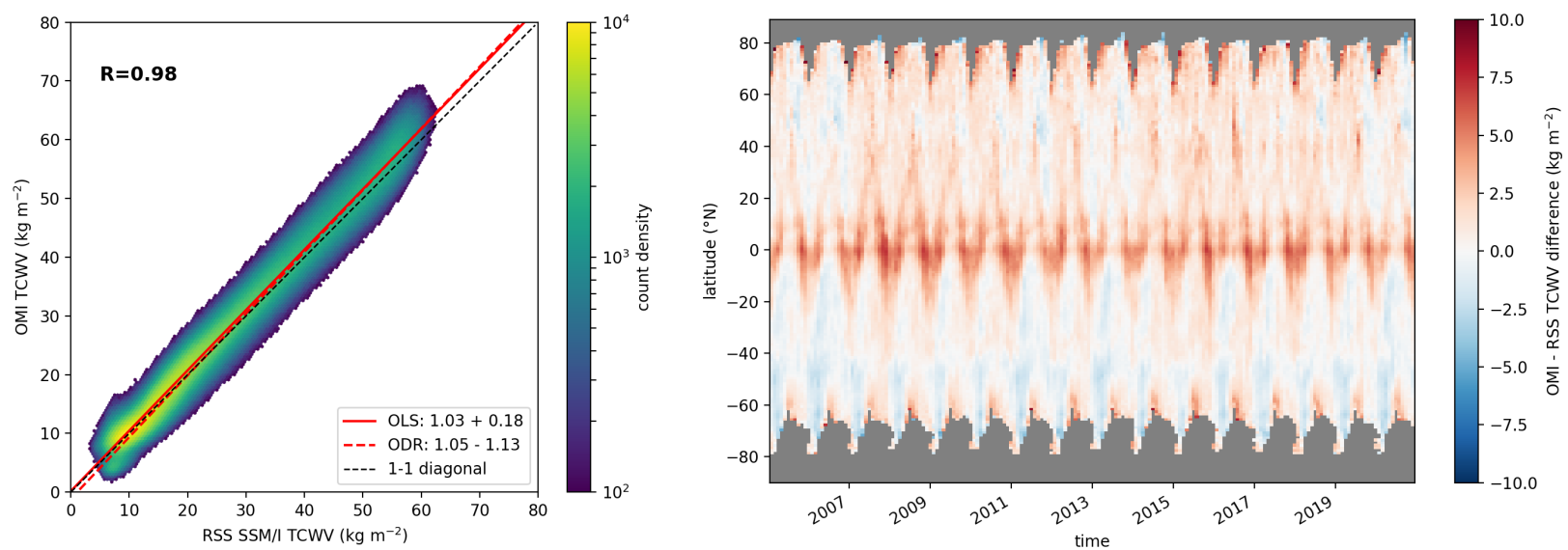

Figure 3. Intercomparison between monthly mean TCWV from OMI and Remote Sensing Systems (RSS) merged SSM/I data set. Left panel: 2D histogram in which the colour indicates the count density; red solid line represents the results of the linear regression (OLS) and the red dashed line the results of the orthogonal distance regression (ODR). The results of the respective fits are given in the bottom right box and the correlation coefficient in the top left corner. The dashed black line indicates the 1-to-1 diagonal. Right panel: TCWV difference of OMI RSS within the latitude-time space; reddish colours indicate an overestimation, blueish colours an underestimation of the OMI TCWV data set.
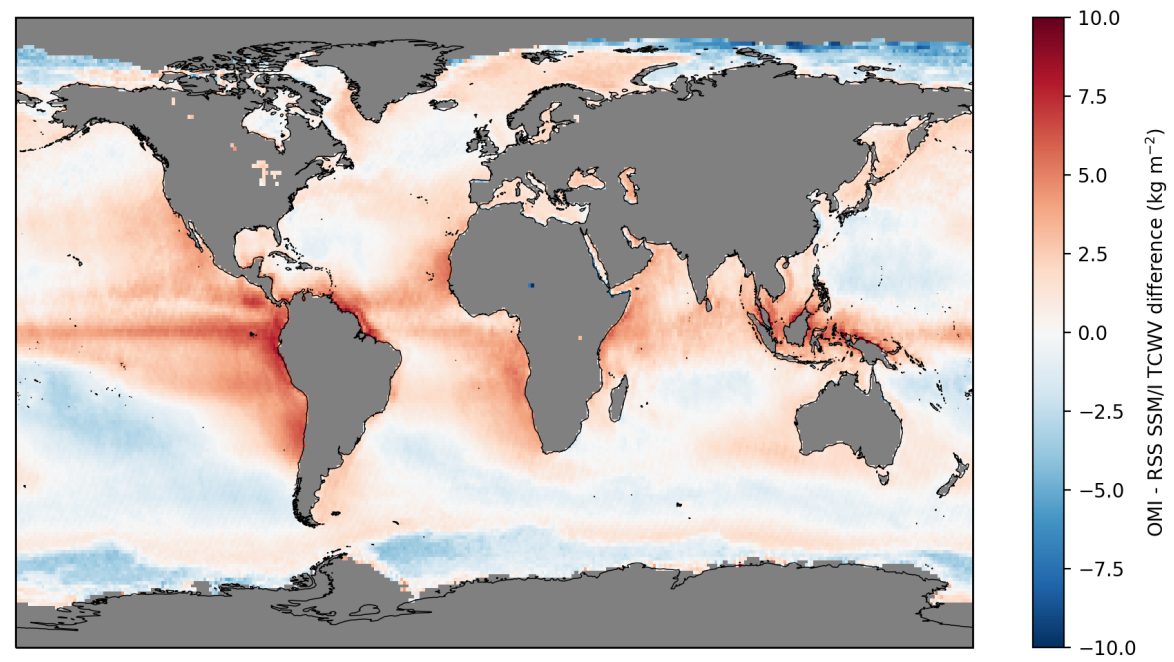

Figure 4. Global mean TCWV difference of OMI minus RSS SSM/I for the time range January 2005 until December 2020. Areas with no valid values are coloured grey. 
https://doi.org/10.5194/essd-2021-319

Preprint. Discussion started: 16 December 2021

(c) Author(s) 2021. CC BY 4.0 License.

(c) (i)

\subsection{Intercomparison to ERA5}

For further validations, we also compare the OMI TCWV data to ERA5 (Hersbach et al., 2020). To account for OMI's observation time (around 13:30 LT), we only take into account ERA5 monthly mean values between 13:00-14:00 LT. The results of the intercomparison to ERA5 are depicted in Figure 5. To investigate potential dependencies on the surface type, we separated the data into data over ocean (top row in Fig. 5) and data over land (bottom row in Fig. 5). The intercomparison for data over ocean reveals similar results as the intercomparison between OMI and RSS: the results of the OLS and ODR indicate a slight overestimation (slopes of around 1.05 and 1.08) together with a correlation coefficient close to unity (R of around 0.98). Moreover, the periodic pattern of positive deviations in the tropics occurs again.

In contrast, the regression results for the intercomparison for data over land reveal a distinctive overestimation by about $11 \%$ for the OLS and slightly less for the ODR (8\%) but still with a high correlation coefficient of 0.97 . Interestingly, the distribution in the 2D histogram (bottom left panel in Fig. 5) shows particularly strong positive deviations of approximately $+10 \mathrm{~kg} \mathrm{~m}^{-2}$ at high TCWV values. Within a piecewise linear regression analysis we find a good agreement to the reference data for TCWV values up to about $26 \mathrm{~kg} \mathrm{~m}^{-2}$ (which represents approximately $74 \%$ of all data points) with slopes of around 0.96 . However, for higher TCWV values we find distinctive positive overestimations of up to $26 \%$.

According to the corresponding latitude-time difference plot (bottom right panel in Fig. 5), the systematic positive deviation in the tropics is now much stronger, however, in other regions the positive deviation is much lower or of similar magnitude as for the ocean comparisons. Closer inspection of the mean TCWV difference between OMI and ERA5 (see Fig. 6) reveals that the strong deviations over the tropical landmasses mainly occur in the regions that are affected by frequent cloud cover such as the Amazon basin, Central Africa and the maritime continent.

Hence, the reasons for the distinctive positive deviations with respect to ERA5 may arise from different causes. For the case of the OMI TCWV retrieval two main uncertainty sources may cause the strong, systematic positive deviations: First, there is the possibility that the used land surface albedo from Borger et al. (2020) is too low, leading to an underestimation of the AMF and consequently to an overestimation of the $\mathrm{H}_{2} \mathrm{O}$ VCD. However, Borger et al. (2020) also showed that their modified albedo map led to overall better results for the case of the TROPOMI TCWV retrieval. On the other hand, there may also be uncertainties in the retrieval input data of the cloud information from $\mathrm{L}_{2} \mathrm{NO}_{2}$ product: If for example the surface albedo is underestimated in the input of the cloud algorithm, this leads to an overestimation of the cloud top height and thus to an underestimation of the AMF, and finally to an overestimation of the $\mathrm{H}_{2} \mathrm{O}$ VCD. For the case of ERA5, the frequent cloud cover can be also major source of uncertainty, as only few satellite measurements (in particular in the thermal infrared) are available due to the frequent cloud contamination which might lead to clear-sky dry biases in the cloud-affected regions. Likewise, these remote regions are affected by an overall sparseness in the observation density of in situ measurements, so the ERA5 TCWV values are likely to be based mainly on modelled data. Overall, the strong positive deviation of the OMI TCWV data set thus likely results from a combination of an overestimation of the OMI TCWV retrieval and an underestimation of the ERA5 data.

215 Thus, considering these large uncertainties in the OMI retrieval and that the uncertainties in ERA5 for data over tropical landmasses are not negligible anymore, we conclude that the OMI TCWV data set can well represent the global distribution of the 

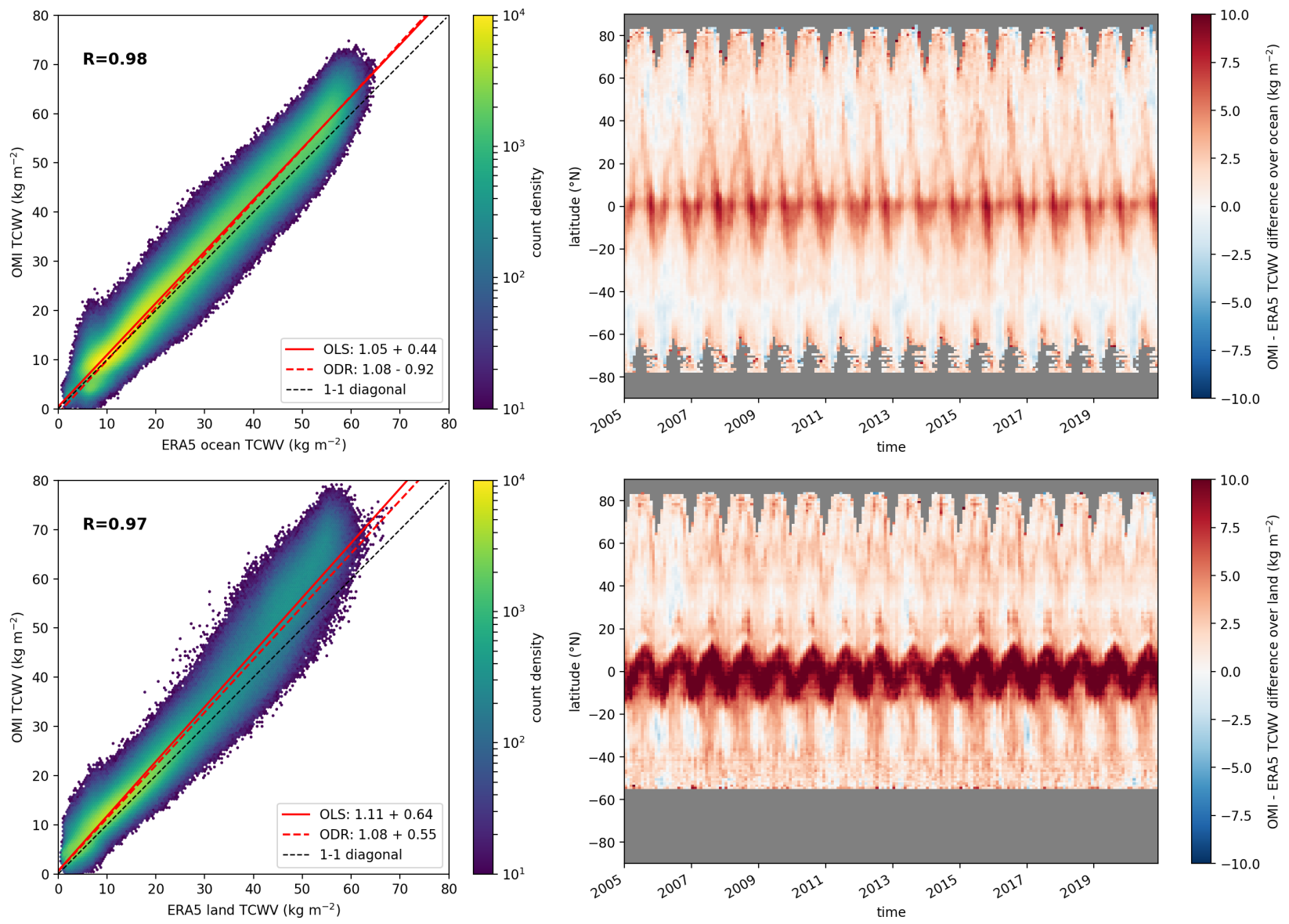

Figure 5. Same as Fig. 3, but now with ERA5 data for data over ocean (top row) and for data over land (bottom row).

atmospheric water vapour content at least over ocean. Over land, however, the data set should be treated with caution due to the systematic positive deviations from the reference data sets, especially in areas of high TCWV values (i.e. above $26 \mathrm{~kg} \mathrm{~m}^{-2}$ ). An additional comparison in which particularly critical regions were filtered using the ESA WV CCI CDR "common mask" (see Fig. B1) is given in the Appendix B. When this mask is applied, only high quality measurements are taken into account for the intercomparison. Consequently, the regression results for the comparison over land improve significantly (see Fig. B3), so that the slopes now vary between 0.95 and 1.02, which are closer to the results of the piecewise-linear regression for TCWV $<26 \mathrm{~kg} \mathrm{~m}^{-2}$.

\subsection{Intercomparison to ESA Water Vapour CCI climate data record}

In addition to RSS SSM/I and ERA5 we compare the OMI TCWV data to the ESA Water Vapour CCI climate data record CDR-2. At the moment of preparation of this manuscript, the CDR-2 is a beta-version of the combined microwave and near- 


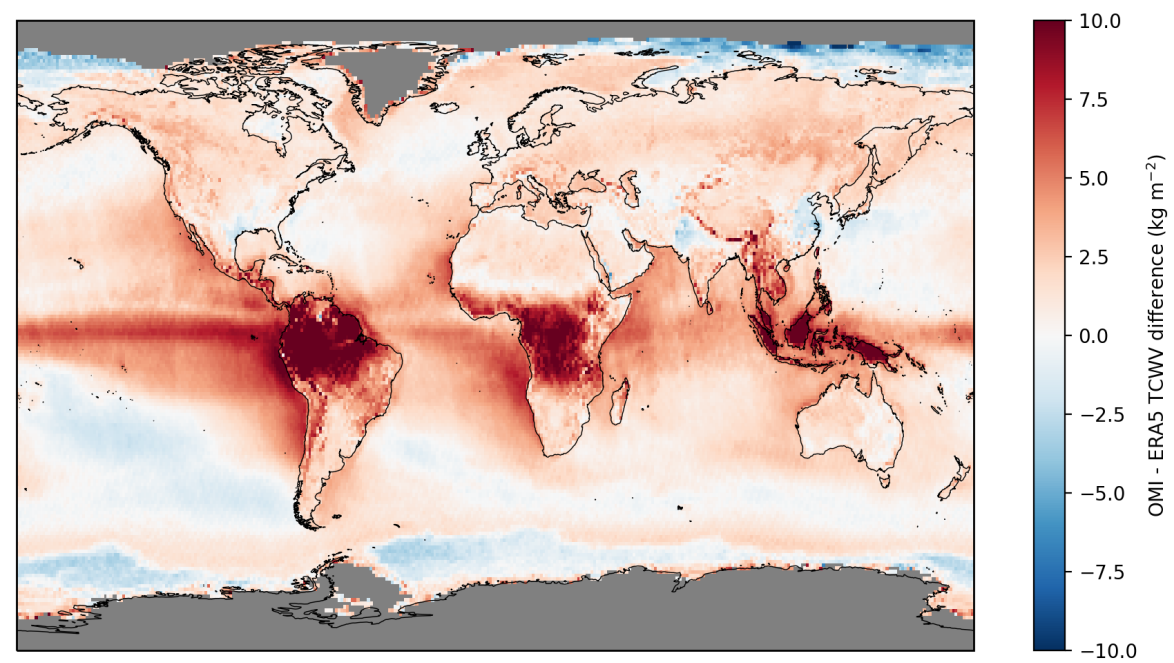

Figure 6. Same as Fig.4, but for ERA5.

infrared imager based TCWV data record (COMBI), whose official release is planned in 2021 by CM SAF. The CDR combines microwave and near-infrared imager based TCWV over the ice-free ocean as well as over land, coastal ocean and sea-ice, respectively. The data record relies on microwave observations from SSM/I, SSMIS, AMSR-E and TMI, partly based on a fundamental climate data record (Fennig et al., 2020) and on near-infrared observations from MERIS, MODIS-Terra and OLCI.

For the intercomparison we resampled the CDR from its native spatial resolution $\left(0.5^{\circ} \times 0.5^{\circ}\right)$ to the lattice of the OMI TCWV data set. Furthermore, though the CDR covers a time span from July 2002 to December 2017, we focus on the time period January 2005 to March 2016, as the CDR's difference relative to ERA5 over land is only stable over the MERIS and MODIS period, i.e., from 2002 until March 2016 if looking at clear-sky data. For the sake of completeness, the results for the comparison over the complete time range are depicted in the Appendix-Figures B4 and B5.

Figure 7 summarizes the results of the intercomparison. Not surprisingly, the results for data over ocean (top row in Fig. 7) are similar to the findings of the RSS SSM/I and ERA5 comparison as measurements from the same (or similar) sensors have been considered: the regression results indicate slight overestimations of around 4-6\% with correlation coefficients of around 0.97. Similar to the intercomparison of ERA5, the intercomparison over land (bottom row in Fig. 7) reveals high overestimations of around 11-14\%. Again, when applying a piecewise linear regression analysis we obtain good agreement with slopes of around 0.94 for TCWV values to about $26 \mathrm{~kg} \mathrm{~m}^{-2}$ but distinctive overestimations of up to $33 \%$ for higher TCWV values. This even higher slope compared to the analysis with ERA5 could be due to the different observation times of the data sets: MERIS on Envisat and MODIS on Terra have an overpass time of 10:00 LT and 10:30 LT, respectively, and follow a descending orbit, whereas OMI measures at 13:30 LT in an ascending orbit which could explain the worse agreement.

Overall, similar to the comparison to ERA5 the strongest positive deviations occur again over the tropical landmasses that are 

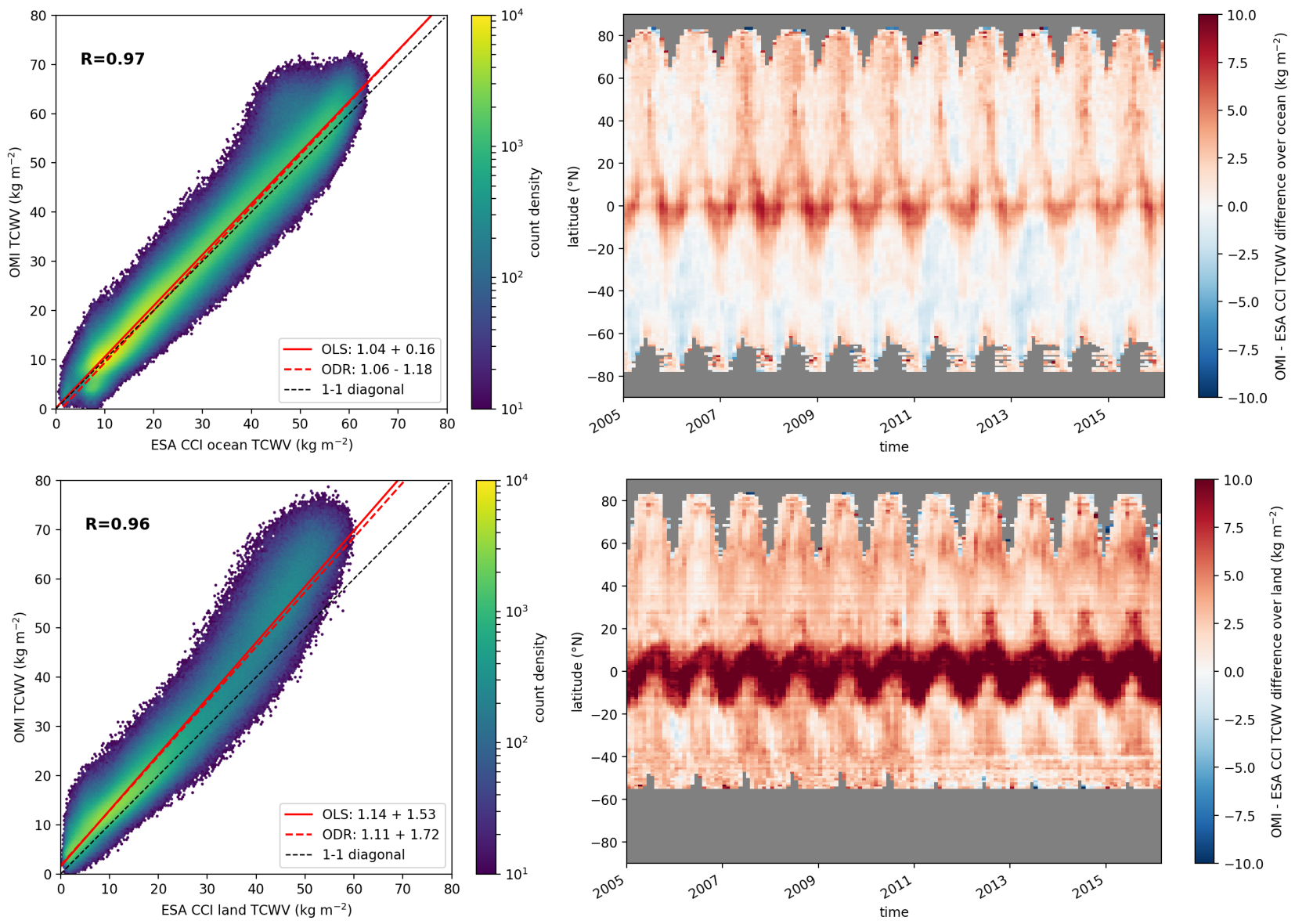

Figure 7. Same as Fig. 3, but now with ESA WV CCI CDR-2 data for data over ocean (top row) and for data over land (bottom row).

mostly affected by frequent cloud cover (see Fig. 8). However, we also observe systematic overestimations along coastlines (e.g. Central America) which eventually arise from sampling issues of the different satellite products and in some mountain regions (e.g. Himalaya).

In Appendix B we present a comparison in which critical regions were filtered using the "common mask" from the ESA WV CCI CDR. When this mask is applied, there are clear improvements for the comparison over land: instead of an overestimation of 11-14\%, a good agreement is obtained with slopes now between 0.97 and 1.04 (see Fig. B3), which agrees quite well with the slopes obtained for the piecewise linear regression for TCWV $<26 \mathrm{~kg} \mathrm{~m}^{-2}$.

\subsection{Temporal stability}

In addition to a good agreement to existing reference data sets, the temporal stability is an important property of a climate data record. As the ESA WV CCI CDR data set only covers the time range up to December 2017, we focus on the comparison 


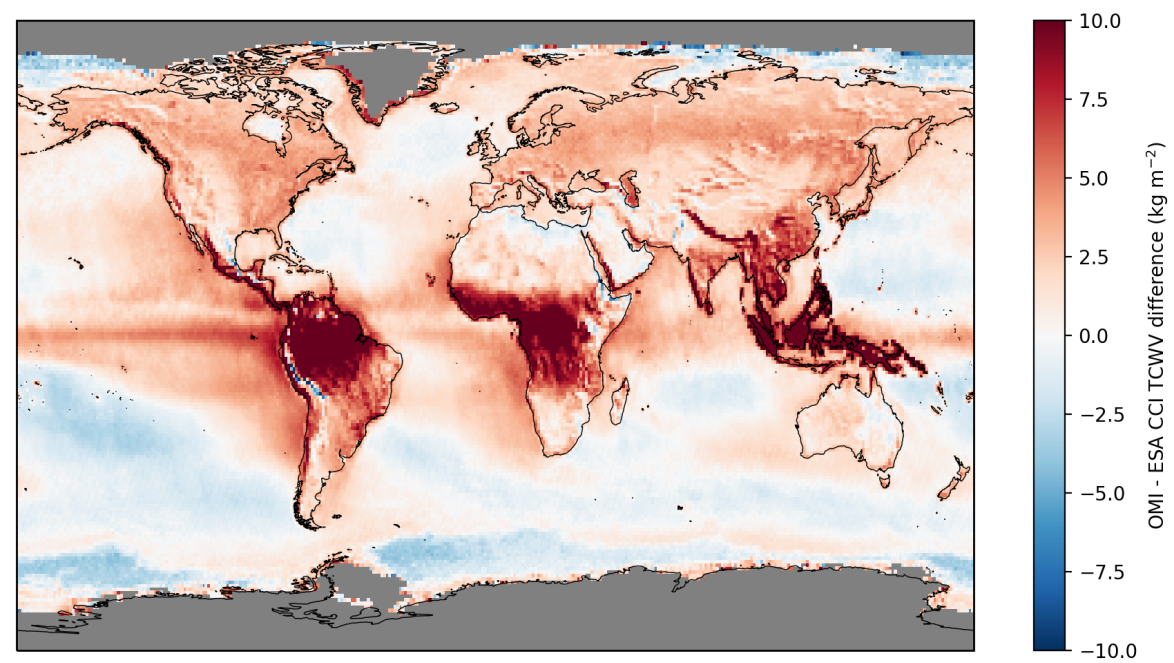

Figure 8. Same as Fig.4, but for ESA WV CCI CDR-2.

to the RSS SSM/I and ERA5 data sets as these two cover the complete time range of OMI TCWV data set. For the sake of completeness, however, we also show the results for ESA WV CCI CDR.

To assess the stability of the OMI TCWV data set, we derive the global mean relative deviation $\bar{\epsilon}$ for every time step:

$\bar{\epsilon}=\frac{\operatorname{mean}\left(\mathrm{OMI}-\mathrm{TCWV}_{\text {ref }}\right)}{\operatorname{mean}(\mathrm{TCWV} \text { ref }}$

and then calculate temporal trends of these deviations using linear regression following the approach of Danielczok and Schröder (2017) and Beirle et al. (2018). For the calculation of global means only data points or grid cells are taken into account for which for every time step data from the OMI TCWV and reference data set are available. In the case of the ESA WV CCI CDR-2 a "common mask" has been provided (see also Fig. B1).

Figure 9 illustrates the temporal variability of the relative differences of the OMI TCWV data set and RSS SSM/I, ERA5, and ESA WV CCI CDR for the time range January 2005 to March 2016 (blue dashed lines) and January 2005 to the end of the respective data set (blue solid lines). For the time series until March 2016 we find trends of $+0.80 \% \mathrm{dec}^{-1}$ for the comparison to RSS SSM/I, $+0.82 \% \mathrm{dec}^{-1}$ for the comparison to ERA5, and $-1.00 \% \mathrm{dec}^{-1}$ for the comparison to the ESA data.

For the time series until the end of the reference data set we find trends of $-0.06 \% \mathrm{dec}^{-1}$ for the comparison to RSS SSM/I and $-0.18 \% \mathrm{dec}^{-1}$ for the comparison to ERA5 and where these trends are not significantly different from $0 \% \mathrm{dec}^{-1}$. For the comparison to the ESA data there is a stronger trend (around $-0.52 \% \mathrm{dec}^{-1}$ ) than for the other two data sets, however also the time range is much shorter and does not cover the complete time range of the OMI TCWV data set. Altogether, the obtained trends of the relative deviations are in line with typical stability requirements for climate data products of $\pm 1 \% \mathrm{dec}^{-1}$ (see e.g. Beirle et al., 2018, and references therein). 

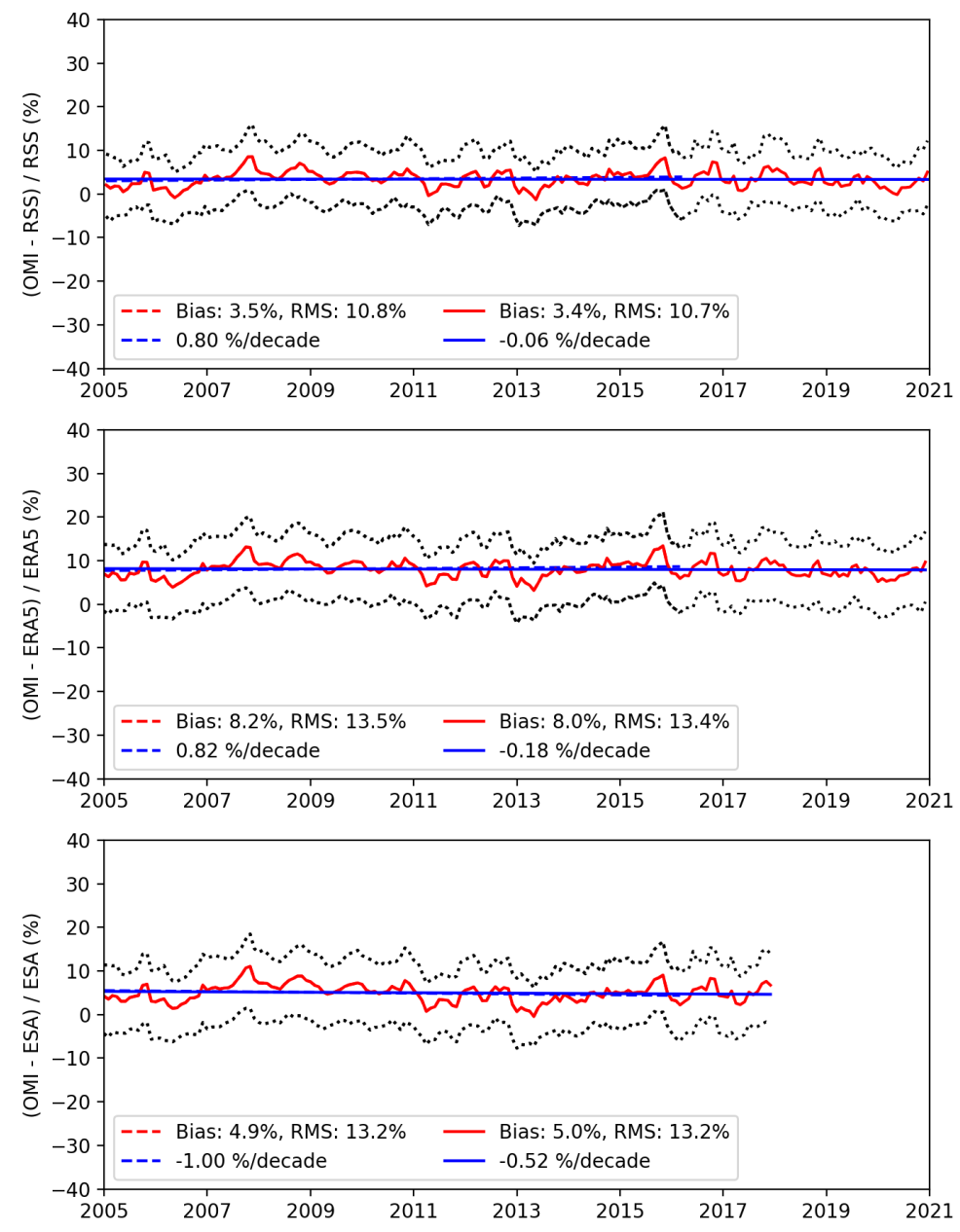

Figure 9. Stability analyses of the global mean relative deviations of the OMI TCWV data set with respect to the ERA5, ESA WV CCI CDR-2, and RSS SSM/I. Red line: global mean relative deviation; blue line: results of linear regression; dotted black line: 25th and 75th percentile, respectively. Dashed lines represent data for the time range from January 2005 to March 2016 and solid lines represent data for the time range from January 2005 to the finish of the respective data set.

\section{Summary}

In this study, we present a long-term 16-year data record of total column water vapour (TCWV) retrieved from multiple years of OMI observations in the visible blue spectral range by means of Differential Optical Absorption Spectroscopy. To derive TCWV from OMI measurements, we applied the TCWV retrieval developed for TROPOMI (Borger et al., 2020) and modified the spectral analysis to account for the degradation of OMI's daily solar irradiance. Thus, annual Earthshine reference spectra were calculated from radiance measurements over Antarctica during December (austral summer).

Within a validation study, the OMI TCWV data set proves to be in good agreement to the reference data sets of RSS SSM/I, 
ERA5, and the ESA WV CCI CDR-2 in particular over ocean surface. However, over land surface the OMI data set systematically overestimates the TCWV content compared to ERA5 and the ESA CDR by approximately $10 \%$ especially in the tropical regions affected by frequent cloud cover. The reasons for these overestimations are manifold, but likely due to an overestimation of the OMI TCWV retrieval due to uncertainties in the retrieval input data (surface albedo, cloud information) on the one hand and an underestimation of the reference data due to missing or uncertain observations on the other hand. Nevertheless, the validation also shows that for TCWV $<26 \mathrm{~kg} \mathrm{~m}^{-2}$ good agreement to the reference data can be obtained and also for the case when regions of large uncertainty are filtered. Considering the temporal stability analysis no significant deviation trends could be obtained with respect to ERA5 and RSS SSM/I which demonstrates that the OMI TCWV data set is well suited for climate studies.

Altogether, the OMI TCWV data set provides a promising basis for investigations of climate change: on the one hand, it covers a long time series (more than 16 years and with measurements still in operation), and on the other hand, these measurements are based on a single instrument, so that no bias corrections between different sensors need to be taken into account (e.g. in trend analysis studies). Although OMI is affected by degradation effects, we were able to successfully suppress these effects by using Earthshine reference spectra. Furthermore, the data set is based on a retrieval in the visible blue spectral range, where a similar sensitivity for the near-surface layers over ocean and land is given and thus a consistent global data set can be obtained from measurements of only one sensor.

In the future, we plan to complement the data set with TCWV measurements from TROPOMI to ensure the continuation of the data set after the end of the OMI mission. Since the TCWV retrieval can be easily applied to other UV-vis satellite instruments, additional data sets from other instruments from past and present missions such as GOME-1/2 and SCIAMACHY, but also to future instruments such as Sentinel-5 on MetOp-SG can be created and eventually combined with the OMI TCWV data set taking into account the different instrumental properties (e.g. observation time). This would allow the construction of a data record that extends from 1995 to today. Similarly, a combination of data from low-earth orbit satellites and geostationary satellite instruments such as GEMS, TEMPO or Sentinel-4 could be a promising option to fill temporal gaps in daily observations, but also to investigate (semi-) diurnal cycles of the water vapour distribution.

\section{Data availability}

The MPIC OMI total column water vapour (TCWV) climate data record is available at https://doi.org/10.5281/zenodo.5776718 (Borger et al., 2021b).

Author contributions. CB performed all calculations for this work and prepared the manuscript together with SB and TW. TW supervised this study. 
https://doi.org/10.5194/essd-2021-319

Preprint. Discussion started: 16 December 2021

(C) Author(s) 2021. CC BY 4.0 License.

(c) (1)

Competing interests. The authors declare that they have no conflict of interest.

Acknowledgements. The combined microwave and near-infrared imager based product COMBI was initiated, funded and provided by the Water Vapour project of the ESA Climate Change Initiative, with contributions from Brockmann Consult, Spectral Earth, Deutscher Wetterdienst and the EUMETSAT Satellite Climate Facility on Climate Monitoring (CM SAF). The combined MW and NIR product will be owned

315 by EUMETSAT CM SAF and will be released by CM SAF in late 2021. In particular, we would like to thank Marc Schröder and the ESA CCI WV team for providing the CDR TCWV and common mask data. 
https://doi.org/10.5194/essd-2021-319

Preprint. Discussion started: 16 December 2021

(c) Author(s) 2021. CC BY 4.0 License.

(c) (1)

\section{Appendix A: Irradiance based vs. Earthshine SCD}

To reduce the across-track biases of the retrieved $\mathrm{H}_{2} \mathrm{O}$ SCDs based on a solar reference spectrum, a destriping algorithm can be performed during post-processing. For instance, one way to destripe the swath of an OMI orbit is to

1. calculate the median SCD for each OMI row along-track,

2. calculate the across-track median SCD from the along-track median SCDs,

3. calculate the deviation of the along-track median SCDs from this across-track median SCD,

4. subtract the deviation from the SCDs of the respective OMI row.

For the case of an Earthshine reference this is already implictly accounted for during the spectral analysis, however, one still has to consider that the Earthshine reference spectrum is not perfectly pristine of the trace gas of interest. For example in our case, although the water vapour concentrations in Antarctica are very low, the Earthshine reference might still be contaminated because of the long light path at such high solar zenith angles.

Figure A1 illustrates the time series of the global monthly mean $\mathrm{H}_{2} \mathrm{O}$ SCDs derived from the annual-mean solar irradiance (and destriped following the aforementioned destriping process) and the Earthshine reference for SZA $<80^{\circ}$. Until 2009 the offset between both SCDs remains constant at values around $0.2 \times 10^{23} \mathrm{molec} \mathrm{cm}^{-2}$. Between 2009 and 2015 the irradiance based SCDs first decrease and then increase distinctively compared to the Earthshine based SCDs and from 2015 onwards a strong increase in the irradiance based SCDs can be observed. In contrast, the Earthshine SCDs show no jumps or steps and remain at the same magnitude after 2015 and over the complete time range in general.

To get an overview of how the SCD difference (i.e. solar irradiance based minus Earthshine SCD) behaves with time over the complete OMI swath, Fig. A2 depicts the monthly mean SCD difference for each OMI row. Between 2005 and 2009 the SCD differences remain quite constant for each row, however, after 2009 artefacts arise first at rows 55-60 and then start to expand to other rows and become even stronger. This clearly illustrates that a OMI TCWV product based on a solar irradiance fit cannot be used for trend analyses. 


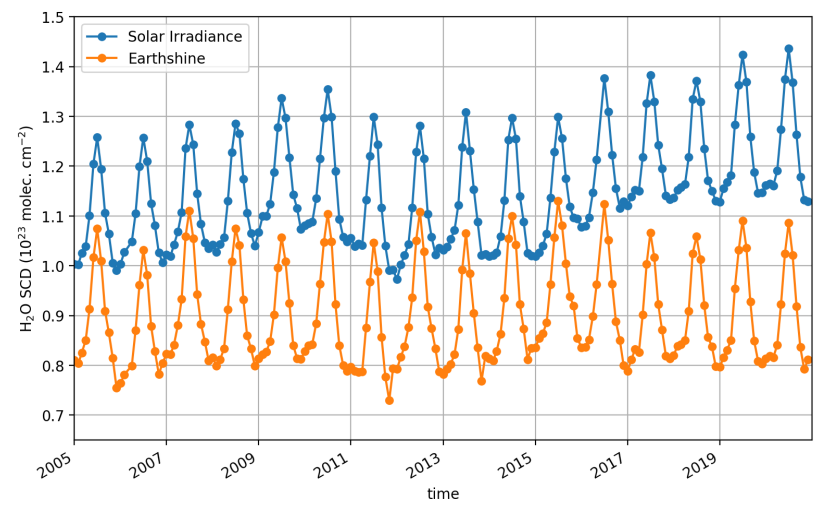

Figure A1. Globally averaged monthly-mean of the destriped $\mathrm{H}_{2} \mathrm{O}$ SCDs derived from annual-mean solar irradiance and $\mathrm{H}_{2} \mathrm{O}$ SCDs derived using the annual Earthshine reference from 2005 until 2020.

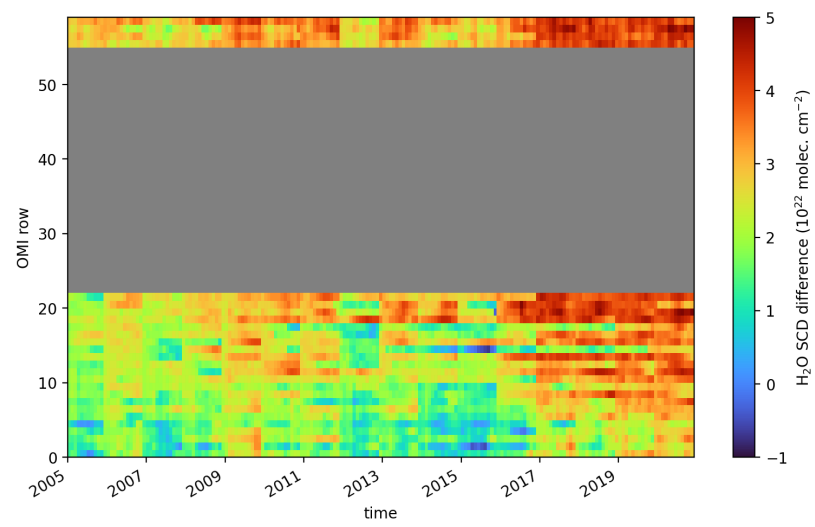

Figure A2. Global mean monthly averaged difference between annual-mean irradiance and Earthshine $\mathrm{H}_{2} \mathrm{O}$ SCD for each OMI row separately. Only observations with a solar zenith angle $<80^{\circ}$ and which are snow- and ice-free are included. Rows affected by the "row-anomaly" (coloured in grey) are excluded for the complete time series. 


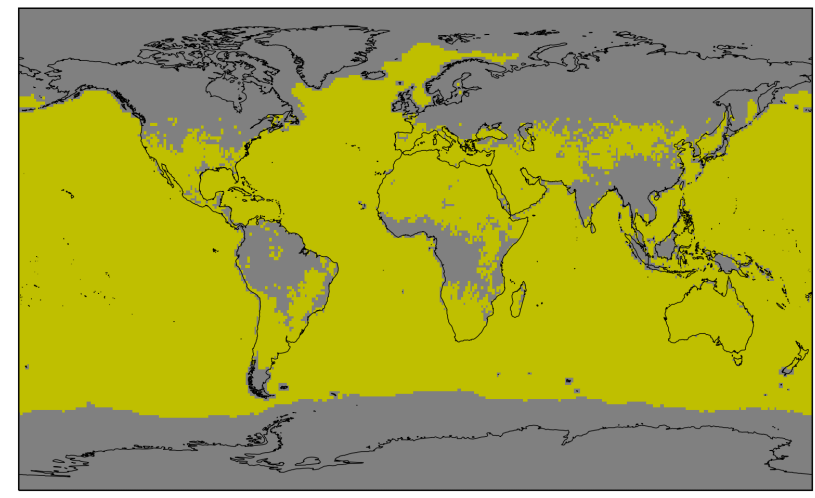

Figure B1. "Common mask" of the ESA WV CCI CDR-2. Yellow grid cells indicate data points which are accounted for within a temporal stability analysis. Invalid grid cells are coloured grey.

\section{Appendix B: Validation taking into account the common mask from ESA WV CCI CDR}

The validation in Sect. 3 also takes into account regions for which only a small number of measurements are available, for example due to frequent cloud cover or seasonality of the solar zenith angle. On the one hand the small sample size of measurements leads to a higher statistical uncertainty with regard to the monthly mean, and on the other hand also to a non-continuous time series when data are missing for the complete month. Moreover, the errors of the individual measurements are also significantly larger in these regions. With the help of the "common-mask" of the ESA WV CCI CDR-2 (see Fig. B1), these regions can be identified and filtered for additional validation.

The results of the validation with the "filtered" data are shown in Fig. B2 for data over ocean and in Fig. B3 for data over land. For all comparisons, the correlation coefficients remain approximately at similar level (i.e. over 0.95) as for the non-"filtered" comparison. For the comparison over ocean we obtain a slight improvement, so that overall the slopes are closer to unity. However, there is a remarkable improvement for the comparison over land: instead of a distinctive overestimation of 8-14\%, the slopes now vary between 0.95 and 1.04, but this is also associated with an increase in the y-axis intercept. Altogether, the results for the "filtered" comparison over land also agree very well to findings of piecewise-linear regression, for which similar regression results in the slope were found for TCWV $<26 \mathrm{~kg} \mathrm{~m}^{-2}$. 
https://doi.org/10.5194/essd-2021-319

Preprint. Discussion started: 16 December 2021

(c) Author(s) 2021. CC BY 4.0 License.
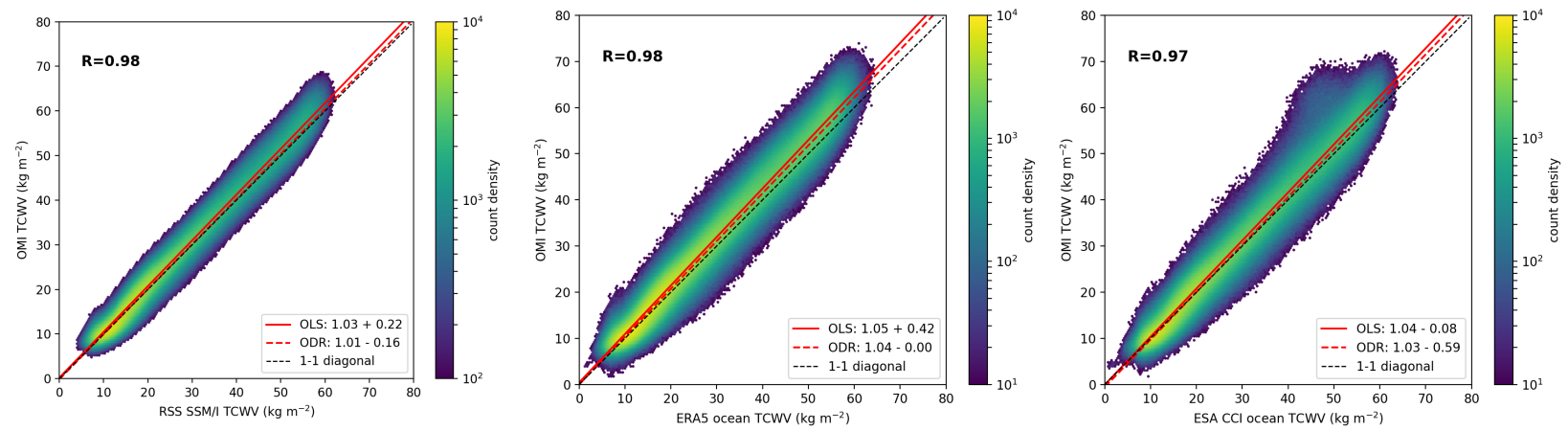

Figure B2. Correlation analysis of the OMI TCWV data set and RSS SSM/I, ERA5, the ESA WV CCI CDR-2 for data over ocean taking into account only valid grid cells according to "common mask" in Figure B1.
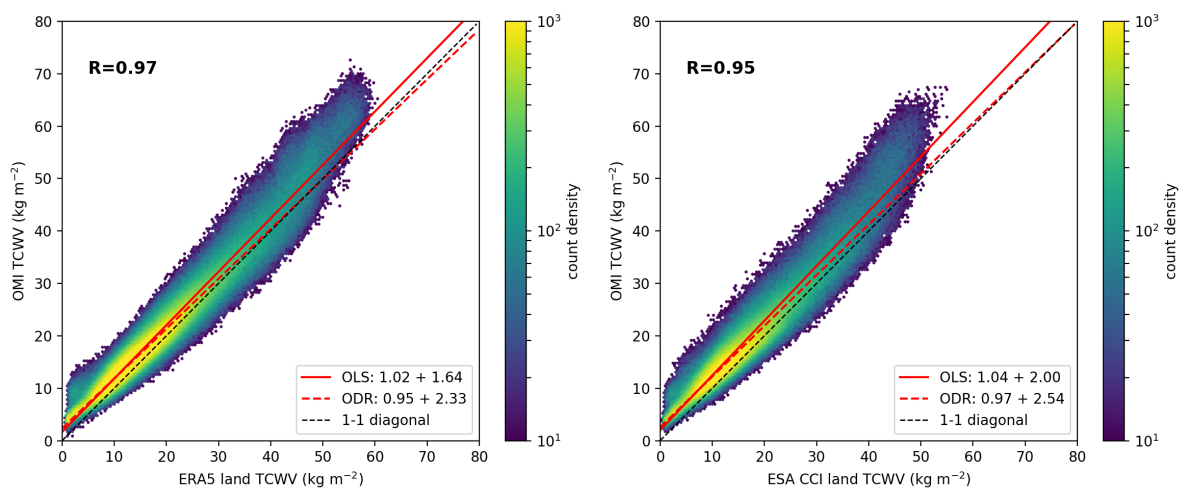

Figure B3. Same as Fig. B2, but for data over land. 

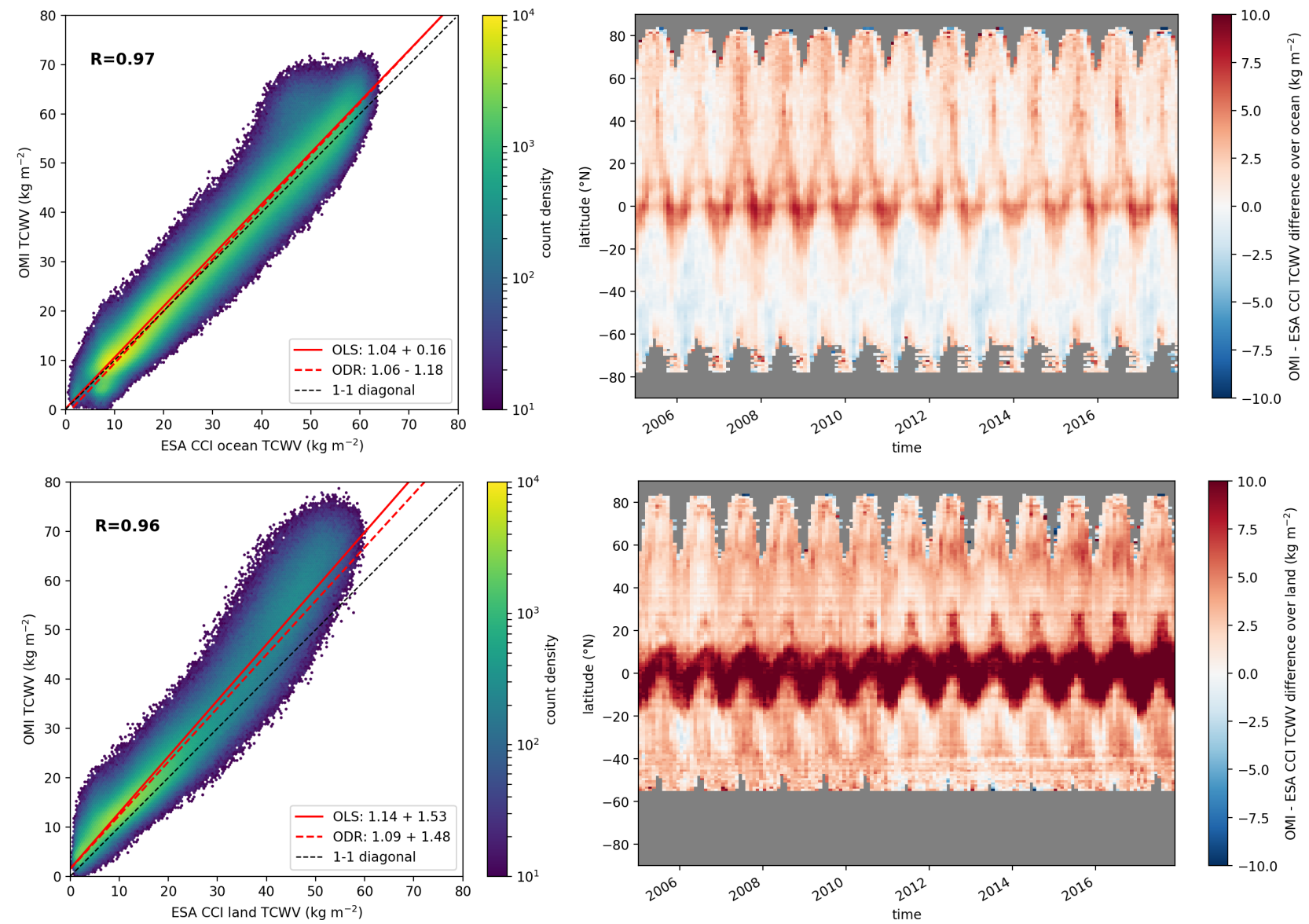

Figure B4. Same as Fig. 7, but now with ESA WV CCI CDR-2 data for data over ocean (top row) and for data over land (bottom row) for the complete time range. 

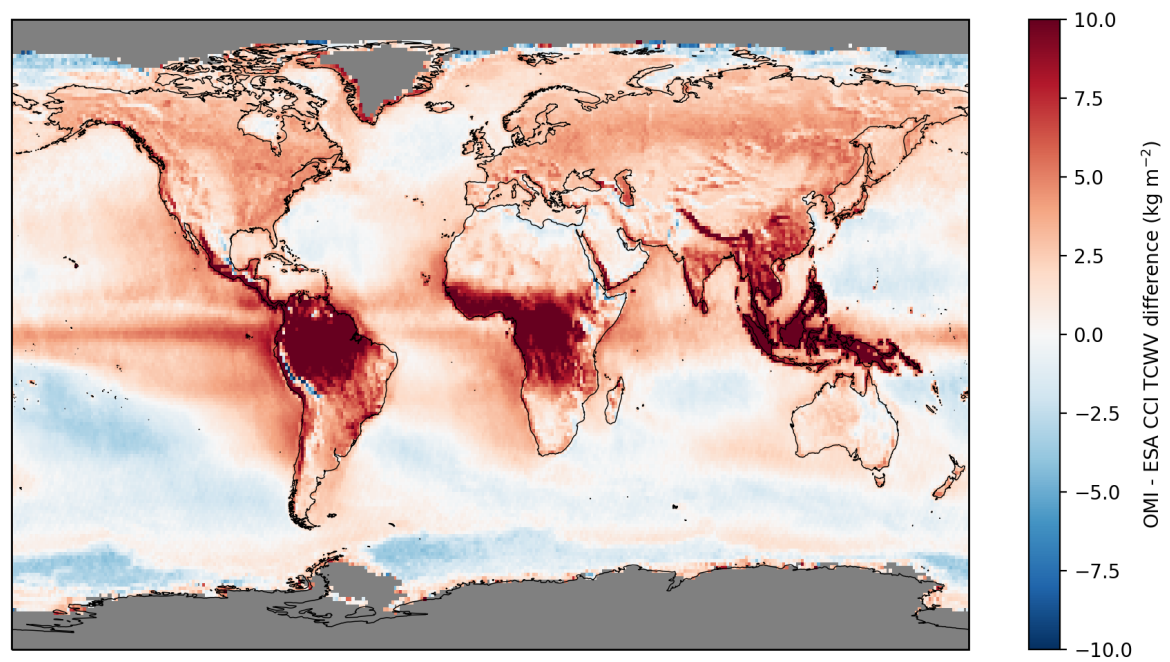

Figure B5. Same as Fig.8, but now for ESA WV CCI CDR data over the complete time range. 
https://doi.org/10.5194/essd-2021-319

Preprint. Discussion started: 16 December 2021

(c) Author(s) 2021. CC BY 4.0 License.

(c) (i)

\section{References}

Anand, J. S., Monks, P. S., and Leigh, R. J.: An improved retrieval of tropospheric $\mathrm{NO}_{2}$ from space over polluted regions using an Earth radiance reference, Atmospheric Measurement Techniques, 8, 1519-1535, https://doi.org/10.5194/amt-8-1519-2015, 2015.

Beirle, S., Lampel, J., Wang, Y., Mies, K., Dörner, S., Grossi, M., Loyola, D., Dehn, A., Danielczok, A., Schröder, M., and Wagner, T.: The ESA GOME-Evolution "Climate" water vapor product: a homogenized time series of $\mathrm{H}_{2} \mathrm{O}$ columns from GOME, SCIAMACHY, and GOME-2, Earth System Science Data, 10, 449-468, https://doi.org/10.5194/essd-10-449-2018, 2018.

Bennartz, R. and Fischer, J.: Retrieval of columnar water vapour over land from backscattered solar radiation using the Medium Resolution Imaging Spectrometer, Remote Sensing of Environment, 78, 274-283, https://doi.org/10.1016/S0034-4257(01)00218-8, 2001.

Boersma, K. F., Eskes, H. J., Richter, A., De Smedt, I., Lorente, A., Beirle, S., van Geffen, J. H. G. M., Zara, M., Peters, E., Van Roozendael, M., Wagner, T., Maasakkers, J. D., van der A, R. J., Nightingale, J., De Rudder, A., Irie, H., Pinardi, G., Lambert, J.-C., and Compernolle, S. C.: Improving algorithms and uncertainty estimates for satellite $\mathrm{NO}_{2}$ retrievals: results from the quality assurance for the essential climate variables (QA4ECV) project, Atmospheric Measurement Techniques, 11, 6651-6678, https://doi.org/10.5194/amt-11-6651-2018, 2018.

Borger, C., Beirle, S., Dörner, S., Sihler, H., and Wagner, T.: Total column water vapour retrieval from S-5P/TROPOMI in the visible blue spectral range, Atmospheric Measurement Techniques, 13, 2751-2783, https://doi.org/10.5194/amt-13-2751-2020, 2020.

Borger, C., Beirle, S., and Wagner, T.: Analysis of global trends of total column water vapour from multiple years of OMI observations, to be submitted to Atmospheric Chemistry and Physics, 2021a.

Borger, C., Beirle, S., and Wagner, T.: MPIC OMI Total Column Water Vapour (TCWV) Climate Data Record, https://doi.org/10.5281/zenodo.5776718, 2021b.

Chan, K. L., Valks, P., Slijkhuis, S., Köhler, C., and Loyola, D.: Total column water vapor retrieval for Global Ozone Monitoring Experience-2 (GOME-2) visible blue observations, Atmospheric Measurement Techniques, 13, 4169-4193, https://doi.org/10.5194/amt-13-4169-2020, 2020.

Danielczok, A. and Schröder, M.: GOME Evolution "Climate" product validation report, resreport, European Space Agency, https://earth. esa.int/documents/700255/1525725/GOME_EVL_L3_ValRep_final/db7e72c3-044d-4236-9dee-d88405b89ef0, 2017.

Fennig, K., Schröder, M., Andersson, A., and Hollmann, R.: A Fundamental Climate Data Record of SMMR, SSM/I, and SSMIS brightness temperatures, Earth System Science Data, 12, 647-681, https://doi.org/10.5194/essd-12-647-2020, 2020.

Gao, B.-C. and Kaufman, Y. J.: Water vapor retrievals using Moderate Resolution Imaging Spectroradiometer (MODIS) near-infrared channels, Journal of Geophysical Research: Atmospheres, 108, https://doi.org/10.1029/2002JD003023, 2003.

Grossi, M., Valks, P., Loyola, D., Aberle, B., Slijkhuis, S., Wagner, T., Beirle, S., and Lang, R.: Total column water vapour measurements from GOME-2 MetOp-A and MetOp-B, Atmospheric Measurement Techniques, 8, 1111-1133, https://doi.org/10.5194/amt-8-1111-2015, 2015.

Held, I. M. and Soden, B. J.: Water Vapor Feedback and Global Warming, Annual Review of Energy and the Environment, 25, 441-475, https://doi.org/10.1146/annurev.energy.25.1.441, 2000.

Hersbach, H., Bell, B., Berrisford, P., Biavati, G., Horányi, A., Muñoz Sabater, J., Nicolas, J., Peubey, C., Radu, R., Rozum, I., Schepers, D., Simmons, A., Soci, C., Dee, D., and Thépaut, J.-N.: ERA5 monthly averaged data on single levels from 1979 to present, Copernicus Climate Change Service (C3S) Climate Data Store (CDS), https://doi.org/10.24381/cds.f17050d7, (Accessed on: 2021-07-01), 2019. 
https://doi.org/10.5194/essd-2021-319

Preprint. Discussion started: 16 December 2021

(c) Author(s) 2021. CC BY 4.0 License.

(c) (i)

Hersbach, H., Bell, B., Berrisford, P., Hirahara, S., Horányi, A., Muñoz-Sabater, J., Nicolas, J., Peubey, C., Radu, R., Schepers, D., Simmons, A., Soci, C., Abdalla, S., Abellan, X., Balsamo, G., Bechtold, P., Biavati, G., Bidlot, J., Bonavita, M., De Chiara, G., Dahlgren, P., Dee, D., Diamantakis, M., Dragani, R., Flemming, J., Forbes, R., Fuentes, M., Geer, A., Haimberger, L., Healy, S., Hogan, R. J., Hólm, E., Janisková, M., Keeley, S., Laloyaux, P., Lopez, P., Lupu, C., Radnoti, G., de Rosnay, P., Rozum, I., Vamborg, F., Villaume, S., and Thépaut, J.-N.: The ERA5 global reanalysis, Quarterly Journal of the Royal Meteorological Society, 146, 1999-2049, https://doi.org/10.1002/qj.3803, 2020.

Kiehl, J. T. and Trenberth, K. E.: Earth's Annual Global Mean Energy Budget., Bulletin of the American Meteorological Society, 78, 197197, https://doi.org/10.1175/1520-0477(1997)078<0197:EAGMEB>2.0.CO;2, 1997.

Kleipool, Q. L., Dobber, M. R., de Haan, J. F., and Levelt, P. F.: Earth surface reflectance climatology from 3 years of OMI data, Journal of Geophysical Research: Atmospheres, 113, https://doi.org/10.1029/2008JD010290, 2008.

Koelemeijer, R. B. A., de Haan, J. F., and Stammes, P.: A database of spectral surface reflectivity in the range 335-772 nm derived from 5.5 years of GOME observations, Journal of Geophysical Research: Atmospheres, 108, https://doi.org/https://doi.org/10.1029/2002JD002429, 2003.

Kursinski, E. R., Hajj, G. A., Schofield, J. T., Linfield, R. P., and Hardy, K. R.: Observing Earth's atmosphere with radio occultation measurements using the Global Positioning System, Journal of Geophysical Research: Atmospheres, 102, 23 429-23 465, https://doi.org/10.1029/97JD01569, 1997.

Lamsal, L. N., Krotkov, N. A., Vasilkov, A., Marchenko, S., Qin, W., Yang, E.-S., Fasnacht, Z., Joiner, J., Choi, S., Haffner, D., Swartz, W. H., Fisher, B., and Bucsela, E.: Ozone Monitoring Instrument (OMI) Aura nitrogen dioxide standard product version 4.0 with improved surface and cloud treatments, Atmospheric Measurement Techniques, 14, 455-479, https://doi.org/10.5194/amt-14-455-2021, 2021.

Lang, R., Williams, J. E., van der Zande, W. J., and Maurellis, A. N.: Application of the Spectral Structure Parameterization technique: retrieval of total water vapor columns from GOME, Atmospheric Chemistry and Physics, 3, 145-160, https://doi.org/10.5194/acp-3-1452003, 2003.

Levelt, P. F., van den Oord, G. H., Dobber, M. R., Malkki, A., Visser, H., de Vries, J., Stammes, P., Lundell, J. O., and Saari, H.: The ozone monitoring instrument, IEEE Transactions on Geoscience and Remote Sensing, 44, 1093-1101, https://doi.org/10.1109/TGRS.2006.872333, 2006.

Levelt, P. F., Joiner, J., Tamminen, J., Veefkind, J. P., Bhartia, P. K., Stein Zweers, D. C., Duncan, B. N., Streets, D. G., Eskes, H., van der A, R., McLinden, C., Fioletov, V., Carn, S., de Laat, J., DeLand, M., Marchenko, S., McPeters, R., Ziemke, J., Fu, D., Liu, X., Pickering, K., Apituley, A., González Abad, G., Arola, A., Boersma, F., Chan Miller, C., Chance, K., de Graaf, M., Hakkarainen, J., Hassinen, S., Ialongo, I., Kleipool, Q., Krotkov, N., Li, C., Lamsal, L., Newman, P., Nowlan, C., Suleiman, R., Tilstra, L. G., Torres, O., Wang, H., and Wargan, K.: The Ozone Monitoring Instrument: overview of 14 years in space, Atmospheric Chemistry and Physics, 18, 5699-5745, https://doi.org/10.5194/acp-18-5699-2018, 2018.

Mears, C. A., Wang, J., Smith, D., and Wentz, F. J.: Intercomparison of total precipitable water measurements made by satelliteborne microwave radiometers and ground-based GPS instruments, Journal of Geophysical Research: Atmospheres, 120, 2492-2504, https://doi.org/10.1002/2014JD022694, 2015.

Munro, R., Lang, R., Klaes, D., Poli, G., Retscher, C., Lindstrot, R., Huckle, R., Lacan, A., Grzegorski, M., Holdak, A., Kokhanovsky, A., Livschitz, J., and Eisinger, M.: The GOME-2 instrument on the Metop series of satellites: instrument design, calibration, and level 1 data processing - an overview, Atmospheric Measurement Techniques, 9, 1279-1301, https://doi.org/10.5194/amt-9-1279-2016, 2016. 
https://doi.org/10.5194/essd-2021-319

Preprint. Discussion started: 16 December 2021

(c) Author(s) 2021. CC BY 4.0 License.

(c) (i)

Noël, S., Buchwitz, M., Bovensmann, H., Hoogen, R., and Burrows, J. P.: Atmospheric water vapor amounts retrieved from GOME satellite data, Geophysical Research Letters, 26, 1841-1844, https://doi.org/10.1029/1999GL900437, 1999.

Platt, U. and Stutz, J.: Differential Optical Absorption Spectroscopy: Principles and Applications, Physics of Earth and Space Environments, Springer Berlin Heidelberg, https://doi.org/10.1007/978-3-540-75776-4, 2008.

Randall, D. A., Wood, R. A., Bony, S., Colman, R., Fichefet, T., Fyfe, J., Kattsov, V., Pitman, A., Shukla, J., Srinivasan, J., et al.: Climate models and their evaluation, in: Climate change 2007: The physical science basis. Contribution of Working Group I to the Fourth Assessment Report of the IPCC (FAR), pp. 589-662, Cambridge University Press, 2007.

Rosenkranz, P. W.: Retrieval of temperature and moisture profiles from AMSU-A and AMSU-B measurements, IEEE Transactions on Geoscience and Remote Sensing, 39, 2429-2435, https://doi.org/10.1109/36.964979, 2001.

Schenkeveld, V. M. E., Jaross, G., Marchenko, S., Haffner, D., Kleipool, Q. L., Rozemeijer, N. C., Veefkind, J. P., and Levelt, P. F.: In-flight performance of the Ozone Monitoring Instrument, Atmospheric Measurement Techniques, 10, 1957-1986, https://doi.org/10.5194/amt10-1957-2017, 2017.

Stevens, B. and Bony, S.: What Are Climate Models Missing?, Science, 340, 1053-1054, https://doi.org/10.1126/science.1237554, 2013.

Sulla-Menashe, D., Gray, J. M., Abercrombie, S. P., and Friedl, M. A.: Hierarchical mapping of annual global land cover 2001 to present: The MODIS Collection 6 Land Cover product, Remote Sensing of Environment, 222, 183 - 194, https://doi.org/10.1016/j.rse.2018.12.013, 2019.

Susskind, J., Barnet, C., and Blaisdell, J.: Retrieval of atmospheric and surface parameters from AIRS/AMSU/HSB data in the presence of clouds, IEEE Transactions on Geoscience and Remote Sensing, 41, 390-409, https://doi.org/10.1109/TGRS.2002.808236, 2003.

Tilstra, L. G., Tuinder, O. N. E., Wang, P., and Stammes, P.: Surface reflectivity climatologies from UV to NIR determined from Earth observations by GOME-2 and SCIAMACHY, Journal of Geophysical Research: Atmospheres, 122, 4084-4111, https://doi.org/10.1002/2016JD025940, 2017.

Trenberth, K. E., Fasullo, J. T., and Kiehl, J.: Earth's Global Energy Budget, Bulletin of the American Meteorological Society, 90 , 311 - 324, https://doi.org/10.1175/2008BAMS2634.1, 2009.

Veefkind, J., Aben, I., McMullan, K., Förster, H., de Vries, J., Otter, G., Claas, J., Eskes, H., de Haan, J., Kleipool, Q., van Weele, M., Hasekamp, O., Hoogeveen, R., Landgraf, J., Snel, R., Tol, P., Ingmann, P., Voors, R., Kruizinga, B., Vink, R., Visser, H., and Levelt, P.: TROPOMI on the ESA Sentinel-5 Precursor: A GMES mission for global observations of the atmospheric composition for climate, air quality and ozone layer applications, Remote Sensing of Environment, 120, 70 - 83, https://doi.org/10.1016/j.rse.2011.09.027, the Sentinel Missions - New Opportunities for Science, 2012.

Wagner, T., Heland, J., Zöger, M., and Platt, U.: A fast $\mathrm{H}_{2} \mathrm{O}$ total column density product from GOME - Validation with in-situ aircraft measurements, Atmospheric Chemistry and Physics, 3, 651-663, https://doi.org/10.5194/acp-3-651-2003, 2003.

Wagner, T., Beirle, S., Sihler, H., and Mies, K.: A feasibility study for the retrieval of the total column precipitable water vapour from satellite observations in the blue spectral range, Atmospheric Measurement Techniques, 6, 2593-2605, https://doi.org/10.5194/amt-6-2593-2013, 2013.

Wang, H., Souri, A. H., González Abad, G., Liu, X., and Chance, K.: Ozone Monitoring Instrument (OMI) Total Column Water Vapor version 4 validation and applications, Atmospheric Measurement Techniques, 12, 5183-5199, https://doi.org/10.5194/amt-12-5183-2019, 2019.

Wentz, F. J.: A 17-Yr Climate Record of Environmental Parameters Derived from the Tropical Rainfall Measuring Mission (TRMM) Microwave Imager, Journal of Climate, 28, 6882 - 6902, https://doi.org/10.1175/JCLI-D-15-0155.1, 2015. 